\title{
Prokineticin 1 induces a pro-inflammatory response in murine fetal membranes but does not induce preterm delivery
}

\author{
Tamsin R M Lannagan ${ }^{1,2}$, Martin R Wilson ${ }^{1}$, Fiona Denison², Jane E Norman², \\ Rob D Catalano ${ }^{1,2}$ and Henry N Jabbour ${ }^{1}$ \\ ${ }^{1}$ MRC Human Reproductive Science Unit and ${ }^{2}$ MRC Centre for Reproductive Health, The Queen's Medical \\ Research Centre, University of Edinburgh, 47 Little France Crescent, Edinburgh EH16 4TY, UK \\ Correspondence should be addressed to T R M Lannagan who is now at CSIRO Animal, Food and Health Sciences, Gate 13, \\ Kintore Avenue, Adelaide, South Australia 5000, Australia; Email: tamsin.lannagan@csiro.au
}

\begin{abstract}
The mechanisms that regulate the induction of term or preterm delivery (PTD) are not fully understood. Infection is known to play a role in the induction of pro-inflammatory cascades in uteroplacental tissues associated with preterm pathological parturition. Similar but not identical cascades are evident in term labour. In the current study, we used a mouse model to evaluate the role of prokineticins in term and preterm parturition. Prokineticins are multi-functioning secreted proteins that signal through G-protein-coupled receptors to induce gene expression, including genes important in inflammatory responses. Expression of prokineticins (Prok1 and Prok2) was quantified in murine uteroplacental tissues by QPCR in the days preceding labour (days 16-19). Prok1 mRNA expression increased significantly on D18 in fetal membranes (compared with D16) but not in uterus or placenta. Intrauterine injection of PROK1 on D17 induced fetal membrane mRNA expression of the pro-inflammatory mediators $I / 6, I / 1 b$, Tnf, Cxcl2 and Cxcl5, which are not normally up-regulated until D19 of pregnancy. However, intrauterine injection of PROK1 did not result in PTD. As expected, injection of lipopolysaccharide (LPS) induced PTD, but this was not associated with changes in expression of Prok1 or its receptor (Prokr1) in fetal membranes.

These results suggest that although Prok1 exhibits dynamic mRNA regulation in fetal membranes preceding labour and induces a proinflammatory response when injected into the uterus on D17, it is insufficient to induce PTD. Additionally, prokineticin up-regulation appears not to be part of the LPS-induced inflammatory response in mouse fetal membranes.

Reproduction (2013) 146 581-591
\end{abstract}

\section{Introduction}

The factors that trigger the onset of parturition at term in humans ( 39 weeks) are not yet fully understood, although inflammation in uteroplacental tissues and increased priming of leukocyte activation in maternal peripheral blood are well documented (Peltier 2003, Haddad et al. 2006, Bollapragada et al. 2009, Challis et al. 2009, Yuan et al. 2009). The cervix and uteroplacental tissues (myometrium, placenta and fetal membranes) demonstrate elevated leukocyte numbers and cytokine production during parturition at term (Denison et al. 1998, Thomson etal. 1999, Young etal. 2002, Osman etal. 2003, 2006). Increased interleukin 1B (IL1B), IL6, IL8 and tumour necrosis factor (TNF) production by recruited and resident immune cells leads to induction of matrix metalloproteinases (MMPs) that facilitate cervical ripening and membrane rupture (Watari et al. 1999, Allport et al. 2001, Kelly 2002, Xu et al. 2002, Young et al. 2002, Timmons et al. 2010). In myometrium, IL1B, IL6 and TNF contribute to the onset and synchronisation of contractions by inducing calcium release and expression of cyclo-oxygenase (COX) enzymes, prostaglandin synthesis and expression of prostaglandin and oxytocin receptors (Friebe-Hoffmann et al. 2001, Tribe et al. 2003, Zaragoza et al. 2006, Fitzgibbon et al. 2009).

Preterm delivery (PTD) in humans is considered to occur before 37 weeks of gestation and is the largest cause of neonatal mortality and morbidity in the developed world (Norman et al. 2009, Beck et al. 2010). Although the aetiology is not fully understood, there are several factors that are associated with increased risk (Goldenberg et al. 2008) including inflammation/infection in the reproductive tract (Goldenberg et al. 2000). Inflammation in uteroplacental tissues can occur in response to bacterial invasion of the reproductive tract as part of the innate immune response (Romero et al. 2006) but also occurs in its absence (Tornblom et al. 2005). The likely sequence of events is that immune cells and tissues expressing toll-like receptors (TLRs) recognise pathogen-associated molecular patterns including lipopolysaccharide (LPS), a component of the cell wall of Gram-negative bacteria. LPS binding to TLR4 (along with CD14 and MD-2) leads to activation of the transcription factor NFKB, a major 
regulator of pro-inflammatory mediators (Akira et al. 2006, Doyle \& O'Neill 2006), resulting in the premature expression of cytokines and chemokines in gestational tissues. This process culminates in early onset of cervical ripening, uterine contractions and PTD. In addition, premature inflammation in uteroplacental tissues is implicated in fetal inflammatory injury, an adverse neonatal outcome (Goepfert et al. 2004). Current therapies for preterm labour attempt to delay the onset of parturition; however, additionally targeting the inflammatory response could not only delay parturition but also reduce fetal inflammatory injury.

Fetal membranes in humans comprise amnion and chorion and an extracellular matrix. At term parturition the fetal membranes overlying the cervix rupture; evidence suggests that this is due to reduced collagen levels and increased apoptosis. However, a role for fetal membrane activation in PTD has also been described as clinical and histological chorioamnionitis (inflammation of the amnion and chorion) can lead to preterm premature rupture of membranes (pPROM) (reviewed by Menon \& Fortunato (2007) and Gomez-Lopez et al. (2010)).

PTD can be artificially induced by treating pregnant mice with LPS (via the i.p., intrauterine, intra-amniotic or vaginal routes), allowing the effect of preterm labour (and potential therapeutic targets) on neonatal morbidity and mortality to be investigated (Elovitz et al. 2003, Pirianov et al. 2009, Burd et al. 2010, Gonzalez et al. 2011).

In silico data (Catalano et al. 2010) suggest that another target of NFKB transcriptional regulation in response to LPS could be the multi-functional secreted proteins prokineticin 1 (PROK1) and PROK2 and their G-protein-coupled receptors (GPCRs: PROKR1 and PROKR2). Prokineticins can regulate a wide variety of biological processes including angiogenesis, haematopoiesis, nociception, circadian rhythms, smooth muscle contractility and inflammatory responses (LeCouter et al. 2001, Li et al. 2001, Negri et al. 2002, Cheng et al. 2005, Dorsch et al. 2005, Maldonado-Perez et al. 2007, Monnier \& Samson 2008, Ngan \& Tam 2008). In relation to pregnancy and parturition, it is also known that prokineticins play a role in establishing early pregnancy (Evans et al. 2008, 2009, Waddell et al. 2011) and in pathological conditions such as pre-eclamspia and ectopic pregnancy (Hoffmann et al. 2006, 2009, Shaw et al. 2010). In addition, we have recently demonstrated that prokineticins are up-regulated at term in uteroplacental tissues and that ex vivo treatment with PROK1 induces a cascade of pro-inflammatory pathways in human placenta and myometrial tissue collected from pregnant women at term (Denison et al. 2008, Gorowiec et al. 2011). These data taken together demonstrate the potential role for prokineticins in regulating inflammatory pathways associated with term parturition and therefore their possible involvement in preterm labour.

This study was designed to characterise the expression of prokineticins in mouse uteroplacental tissues in the days preceding labour and to investigate the role of prokineticins in term and preterm parturition using a mouse model of infection-induced PTD .

\section{Materials and methods}

\section{Mouse model of PTL}

CD1 outbred, timed pregnant mice were purchased from Charles River (Margate, Kent, UK) and allowed at least 6 days of acclimatisation prior to surgery. Pregnant females or virgin female and proven males were purchased pregnant and timedmated within the University of Edinburgh facility. Surgery was performed on day 17 of pregnancy (D17; day plug found is D1 of pregnancy). Dams were anaesthetised with isoflurane and both uterine horns exposed following laparotomy. The number of viable fetuses in each horn was recorded and the horn containing the most fetuses was selected for intrauterine injection. Using a 33-gauge Hamilton syringe, pregnant mice were injected between the two most anterior fetuses with either a $25 \mu \mathrm{l}$ volume of sterile saline (Sigma); recombinant mouse PROK1 (R\&D Systems, Abingdon, Oxford, UK) diluted to $350 \mathrm{nM}$ in saline (dose based on highest concentration shown to induce cell proliferation in bovine endothelial cells in vitro, $\mathrm{ED}_{50}$ of $4 \mu \mathrm{g} / \mathrm{ml}$, determined by R\&D Systems, and nearly ten times the dose that induces cytokine expression in human gestational tissues (Maldonado-Perez et al. 2009); or $20 \mu \mathrm{g}$ LPS (Sigma) in saline (see Table 1 for summary of treatments and sample sizes). The body wall was closed using a continuous suture and the skin closed using single stitches. Dams received Vetergesic analgesia (Reckitt Benckiser Healthcare, Kingstonupon-Thames, UK) and were allowed to recover in a warm environment prior to single housing and monitoring for delivery (infra-red cameras and digital video recorder purchased from RF Concepts (Dundonald, UK)). The time to delivery was the number of hours recorded from injection to delivery of the first pup. To record the time taken for natural delivery (in the absence of surgery), the average time of saline injection was calculated and used as a theoretical time point from which to calculate the time to delivery. Pup survival was calculated as the number of live pups found in the cage (or dam) at the time of culling as a proportion of the total number of viable fetuses recorded at injection. Animals were housed under standard conditions and had access to food and water ad libitum. All animal care and experimental protocols were approved by the animal ethics committee of the University of Edinburgh and the Home Office of the UK government.

\section{Amniotic fluid collection, tissue harvesting and processing}

Tissue was collected from timed-mated CD1 mice on D16-19 of pregnancy (parturition occurred on D20). Dams were culled

Table 1 Treatments and sample size for mouse model of PTL.

\begin{tabular}{lc}
\hline Treatment group & Number of dams \\
\hline Natural delivery & 5 \\
Saline & 15 \\
LPS & 10 \\
PROK1 & 16 \\
\hline
\end{tabular}


Table 2 Treatments and sample size for gestational tissue and in vivo experiments.

\begin{tabular}{llc}
\hline Tissue sample & $\begin{array}{l}\text { Stage of gestation/ } \\
\text { treatment }\end{array}$ & $\begin{array}{c}\text { Number of dams/ } \\
\text { samples collected } \\
\text { per dam }\end{array}$ \\
\hline Fetal membranes & D16 gestation & $10 / 1$ \\
Fetal membranes & D17 gestation & $9 / 1$ \\
Fetal membranes & D18 gestation & $10 / 1$ \\
Fetal membranes & D19 gestation & $10 / 1$ \\
Fetal membranes & D17 6 h saline & $4 / 3$ \\
Fetal membranes & D17 6 h LPS & $4 / 3$ \\
Fetal membranes & D17 6 h PROK1 & $6 / 3$ \\
Amniotic fluid & D17 6 h saline & $4 / 4-6$ \\
Amniotic fluid & D17 6 h LPS & $4 / 4-6$ \\
Amniotic fluid & D17 6 h PROK1 & $\geq 5 / 4-6$ \\
\hline
\end{tabular}

by cervical dislocation and uterus, placenta and fetal membranes separated, and collected into RNAlater (Ambion (Life Technologies Ltd, Paisley, UK)) for RNA extraction or fixed in $4 \%$ neutral buffered formalin and wax embedded for immunohistochemistry (see Table 2 for summary of treatments and sample sizes). Similar collection protocols were applied 2 or $6 \mathrm{~h}$ after intrauterine injection of saline, LPS or PROK1 (as described earlier for the mouse model of PTD). In addition, for the 6 -h time point, amniotic fluid was collected and pooled from four to six fetuses (i.e. one sample per dam).

\section{TaqMan quantitative RT-PCR}

Total RNA was extracted from tissue using QIAzol lysis reagent, phase lock tubes and the RNeasy mini kit with on-column DNase digestion from Qiagen, according to the manufacturer's guidelines. RNA concentration was quantified using a Nanodrop (Thermo Scientific, Hemel Hempstead, UK) and diluted to $100 \mathrm{ng} / \mu \mathrm{l}$ in RNase-free water (Invitrogen) before RT using the Superscript VILO cDNA synthesis kit (Invitrogen). PCRs were carried out using Applied Biosystems 7500 and 7900 Fast instruments. Primer and FAM (6-carboxyfluorescein)-labelled probe sequences were designed to span an intron (where possible) and purchased from Sigma (Table 3) or TaqMan Gene Expression Assays were purchased from Applied Biosystems (Table 4). Expression was normalised for RNA loading using actin (Actb) primers designed to span an intron and JOE-labelled probe (Sigma; Table 3). Relative expression in each sample was calculated against the level of expression detected in a tissue known to express the target gene (Tables 3 and 4). To compare the changes in proinflammatory mediator expression in response to intrauterine injection of LPS or PROK1 with those occurring endogenously at term, fold changes were calculated by dividing the mean relative expression in the treated group by the mean relative expression in the saline group, and by dividing mean relative expression on D19 with that on D17 (the day on which surgery was carried out).

\section{Immunohistochemistry}

Paraffin-embedded tissue was processed for immunohistochemistry as described in Catalano et al. (2011) with either rabbit anti-human PROK1 at 1:750 dilution (Phoenix
Pharmaceuticals (Belmont, CA, USA), H-023-59) or rabbit anti-human PROKR1 at 1:750 dilution (Caltag Medsystems, Buckingham, UK; LS-A6684). Negative controls were incubated without primary antibody. Sections were imaged using a Provis AX70 microscope (Olympus, Southend-on-Sea, UK) and photographed using an AxioCam HRc with AxioVision Release 4.8 (Carl Zeiss Ltd., Berlin, Germany).

\section{Cytokine assays}

Amniotic fluid collected from saline-, LPS- or PROK1-treated dams was quantified by ELISA Quantikine Kits (R\&D Systems) for mouse IL1B (MLB00B), TNF (MTA00) and CXCL2 (MM200) as per kit instructions.

\section{Statistical analysis}

Data that passed the normality test (Kolmogorov-Smirnov) were subjected to statistical analysis using a one-way ANOVA with Tukey's multiple comparison post-test or a two-tailed unpaired $t$-test. Nonparametric data were subjected to KruskalWallis test with Dunn's post-test or a two-tailed Mann-Whitney $U$ test. Percentages were arcsine transformed prior to analysis as they cannot be normally distributed (no values $<0$ and nothing $>100$ ). Where more than one fetus was collected per dam the data was averaged per dam. All analysis was carried out using GraphPad Prism and GraphPad Software, Inc. (La Jolla, CA, USA). Significance was defined as $P<0.05$.

\section{Results}

\section{Expression of prokineticins in murine uteroplacental tissues across the days preceding parturition}

Expression of Prok1 and Prokr1 mRNA was examined daily in fetal membranes from D16 to 19 of pregnancy

Table 3 Sequences of mouse primers and probes used in QPCR.

\begin{tabular}{|c|c|c|}
\hline Gene & Primer/probe sequence $\left(5^{\prime}-3^{\prime}\right)$ & Control tissue \\
\hline Prok1 & $\begin{array}{l}\text { F: GAAGCCACAAGATCCCCTTCT } \\
\text { R: TGCCGTCCGGGAACCT } \\
\text { Probe (FAM/TAM): AAACGCCAA- } \\
\text { CACCATACCTGTCCCTG }\end{array}$ & D19 fetal membrane \\
\hline Prokr1 & $\begin{array}{l}\text { F: TGGCCCGCTACAAAAAGCT } \\
\text { R: CCACGAGGAAGTCT- } \\
\text { GAAATGG } \\
\text { Probe (FAM/TAM): CGCAACCT- } \\
\text { CACCAACCTGCTTATCG }\end{array}$ & Adult liver \\
\hline 116 & $\begin{array}{l}\text { F: CCACGGCCTTCCCTACTTC } \\
\text { R: TGCACAACTCTTTTCT- } \\
\text { CATTCCA } \\
\text { Probe (FAM/TAM): TCACAGAG- } \\
\text { GATACCACTCCCAACA- } \\
\text { GACCTG }\end{array}$ & D19 fetal membrane \\
\hline Ptgs2 & $\begin{array}{l}\text { F: GCTTCGGGAGCACAACAG } \\
\text { R: TGGTTTGGAATAGTTGCTC } \\
\text { Probe (FAM/TAM): TGTGCGACA- } \\
\text { TACTCAAGCA }\end{array}$ & D19 fetal membrane \\
\hline$A c t b$ & $\begin{array}{l}\text { F: GCTTCTTTGCAGCTCCTTCGT } \\
\text { R: GCGCAGCGATATCGTCATC } \\
\text { Probe (JOE/TAM): CACCCGC- } \\
\text { CACCAGTTCGCCAT }\end{array}$ & NA \\
\hline
\end{tabular}


Table 4 Mouse ABI TaqMan gene expression assays used in QPCR.

\begin{tabular}{lll}
\hline Gene & ABI assay code & Control tissue \\
\hline Prok2 & Mm01182450_g1 & D16 uterus \\
Prokr2 & Mm00769571_m1 & D16 uterus \\
Cxcl2 & Mm00436450_m1 & D19 fetal membrane \\
Cxcl5 & Mm00436451_g1 & D19 fetal membrane \\
II1b & Mm01336189_m1 & D19 uterus \\
Tnf & Mm00443258_m1 & D19 uterus \\
Ptgs1 & Mm00477214_m1 & D19 uterus \\
\hline
\end{tabular}

(animals delivered on D20 of pregnancy; one fetal membrane from a minimum of nine to ten dams). On D18, expression of Prok1 mRNA was significantly greater when compared with expression on D16 and 17 ( $P<0.001$; Fig. 1A) and Prokr1 expression was significantly lower on D18 and 19 when compared with D16 ( $P<0.01$ and $P<0.05$ respectively; Fig. 1B).

Protein expression of PROK1 and PROKR1 in fetal membranes was investigated by immunohistochemistry between D16 and 19. No change in localisation was observed during this period, although PROK1 expression was stronger in D19 fetal membranes than those in D16 (Fig. 2, D17-18, not shown). PROK1 and PROKR1 were localised in the amnion epithelium (Fig. 2A, C, F and H). In the yolk sac (considered to be equivalent to the human chorion), PROK1 and PROKR1 were localised to the epithelium, mesoderm and endothelial cells (Fig. 2B, D, G and H).

Expression analysis of Prok 1 in the uterus and placenta revealed no significant change across D16-19 (one tissue sample from a minimum of four to five dams; Supplementary Figure $1 \mathrm{~A}$ and $\mathrm{C}$, see section on supplementary data given at the end of this article). Prokr1 expression decreased towards the end of gestation in the uterus (D19 vs D16 and 17, $P<0.05$; Supplementary Figure 1B) and placenta (D19 vs 17, $P<0.05$; Supplementary Figure 1D).

Expression of Prok2 and Prokr2 was also examined in the same uteroplacental tissue samples from D16 to 19. Fetal membrane Prok2 expression increased by a small but significant amount on D18 when compared with expression on D16 ( $P<0.05$; Supplementary Figure 2A, see section on supplementary data given at the end of this article). No changes were detected for Prokr2 in the fetal membranes (Supplementary Figure 2B). No significant changes were detected for either Prok2 or Prokr2 in the uterus and placenta (Supplementary Figure 2C, D, E and F).

\section{Intrauterine injection of LPS or PROK1 enhances expression of pro-inflammatory mediators in fetal membranes}

LPS treatment is well documented to induce proinflammatory responses in many tissues. In this study, we investigated the pro-inflammatory response of fetal membranes to LPS and PROK1 in vivo using a model of infection-induced PTD. For this, fetal membranes were collected $6 \mathrm{~h}$ after intrauterine injection with saline (control; average of three fetal membranes collected from each of four dams), LPS (average of three fetal membranes collected from each of four dams) or PROK1 (average of three fetal membranes collected from each of six dams). Compared with the saline treatment, relative expression of prostaglandin synthase 2 (Ptgs2, also referred to as COX2), $\|/ 6\| 11 b,, T n f$, chemokine (CXC motif) ligand $2(\mathrm{CxCl})$ and $\mathrm{Cxc} / 5$ mRNAs were found to be significantly increased in response to LPS treatment (Fig. 3). By contrast, expression of Ptgs1 (a gene chosen as a negative control) did not change in response to treatment with LPS. Similarly, Prok1 and Prokr1 expression levels were not regulated by LPS treatment

A

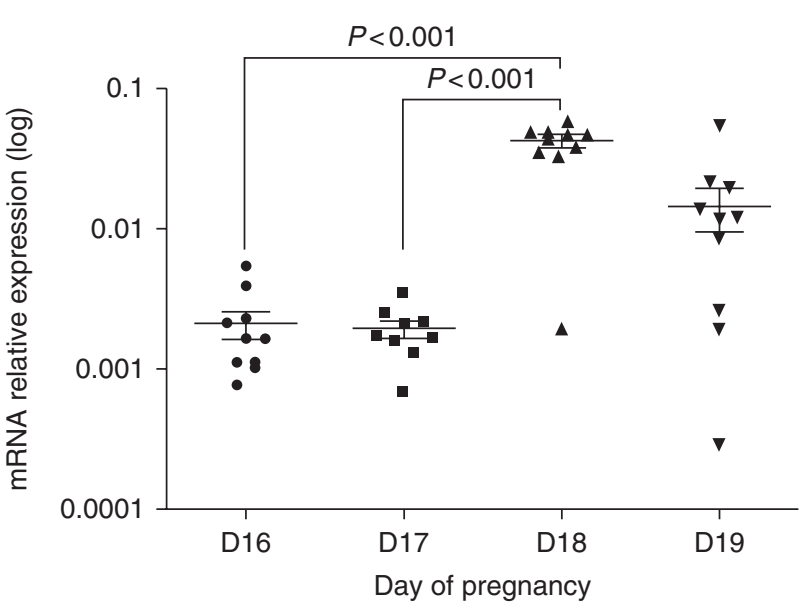

B

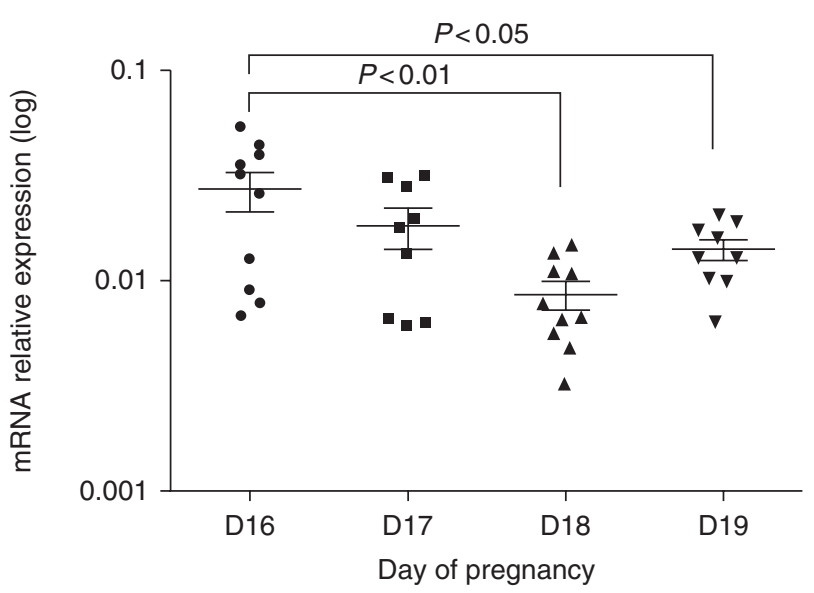

Figure 1 Prok1 mRNA expression peaks on D18 of pregnancy in murine fetal membranes. QPCR expression analysis of Prok1 (A) and Prokr1 (B) in murine fetal membranes reveals dynamic regulation preceding labour (D16-19). The graphs show individual values for each sample (one membrane analysed per mouse), mean expression levels are in arbitrary units normalised to Actb mRNA, error bars represent \pm S.E.M. (ANOVA). D16 $(n=10), \mathrm{D} 17(n=9), \mathrm{D} 18(n=10)$ and D19 $(n=10)$. Note: logarithmic scale. 

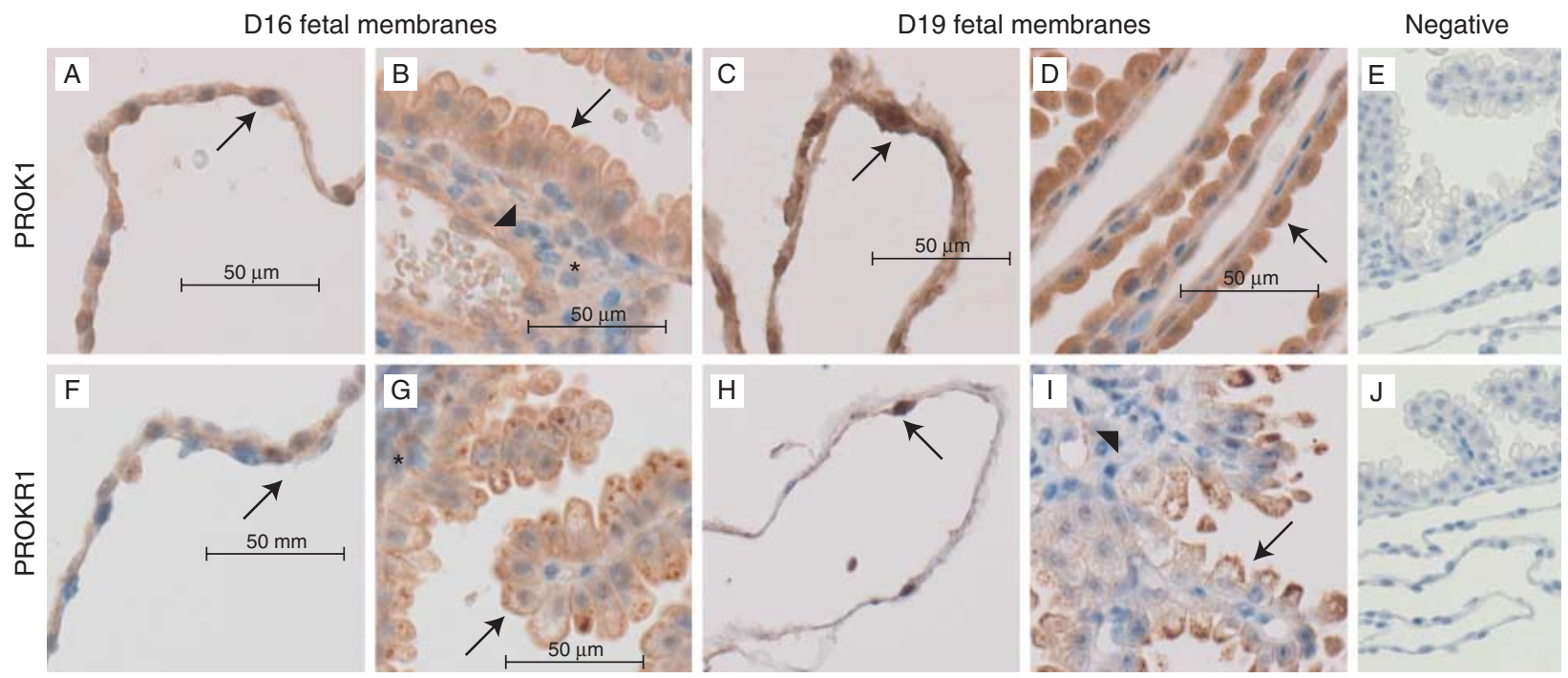

Figure 2 PROK1 and PROKR1 are expressed at the protein level by murine fetal membranes preceding labour. Immunohistochemical localisation of PROK1 (A, B, C and D) and PROKR1 (F, G, H and I) in D16 (A, B, F and G) and D19 (C, D, H and I) murine fetal membranes revealed that PROK1 is localised in the epithelium of amnion and yolk sac (see arrows in (A, B, C and D)) and in mesenchyme (asterisk) and endothelium (arrowhead) of the yolk sac (B). PROKR1 is expressed in the epithelium of amnion and yolk sac (see arrows in $(\mathrm{F}, \mathrm{G}, \mathrm{H}$ and $\mathrm{I})$ ) and in mesenchyme (asterisk in $(\mathrm{G})$ ) and endothelium of yolk sac (arrowhead in (I)). (E and J) Negative controls for PROK1 and PROKR1 respectively.

at the 6-h time point (Fig. 3) or earlier at $2 \mathrm{~h}$ (data not shown). Intrauterine administration of PROK1 significantly increased expression of $1 / 6, \quad / 1 \mathrm{~b}, \mathrm{Tnf}$, Cxcl2 and Cxcl5 but not Ptgs2 or Ptgs 1 by $6 \mathrm{~h}$ after treatment (Fig. 4).

We subsequently investigated the temporal expression of Ptgs2, Il6, II1b, Tnf, CxCl2 and Cxcl5 between D16 and 19 of pregnancy and all were shown to significantly increase on D19 in fetal membranes (Supplementary Figure 3, see section on supplementary data given at the end of this article). Using relative expression values, we compared the endogenous changes occurring in fetal membranes at the onset of parturition with those occurring in response to PROK1 or LPS (Table 5). Endogenous levels on D19 were compared with levels on D17. Apart from Tnf, overall expression of proinflammatory genes in response to intrauterine injection of $350 \mathrm{nM}$ PROK1 was comparable (less than twofold greater) or lower than seen endogenously on D19 of pregnancy. Intrauterine injection of $20 \mu \mathrm{g}$ LPS resulted in
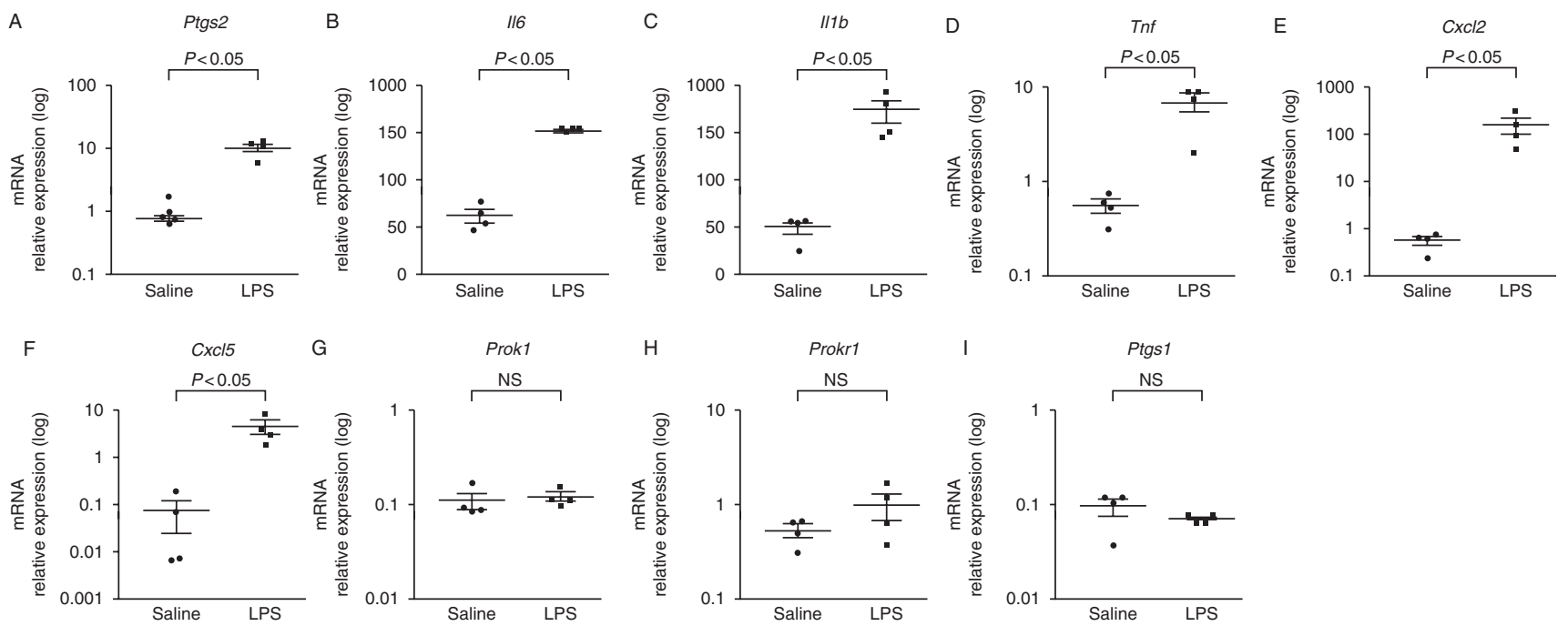

Figure 3 Intrauterine injection of LPS induces a pro-inflammatory response in murine fetal membranes but does not regulate Prok1 or Prokr1. QPCR mRNA expression analysis of (A) Ptgs2, (B) I/6, (C) I/1b, (D) Tnf, (E) Cxcl2, (F) Cxcl5, (G) Prok1, (H) Prokr1 and (I) Ptgs1 in murine fetal membranes 6 h after intrauterine injection of LPS reveals up-regulation of pro-inflammatory mediators but not of Prok1, Prokr1 or Ptgs1 (negative control). The graphs show mean values for each dam (three membranes analysed per dam), mean expression levels are in arbitrary units normalised to Actb mRNA, error bars represent \pm S.E.M. $(t$-test). Saline $(n=4$ dams) and LPS ( $n=4$ dams). NS, non-significant. Note: logarithmic scale. 


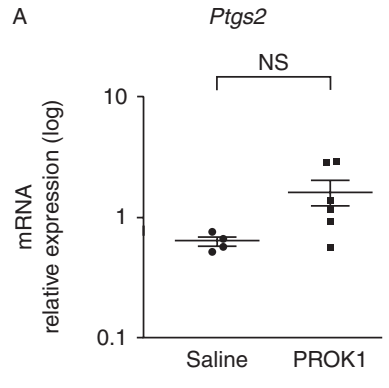

C

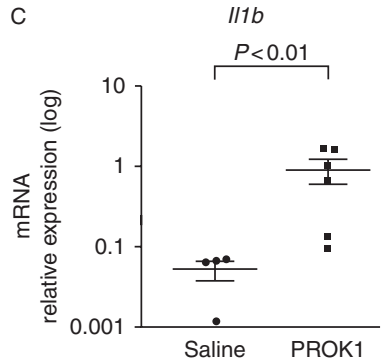

$E$
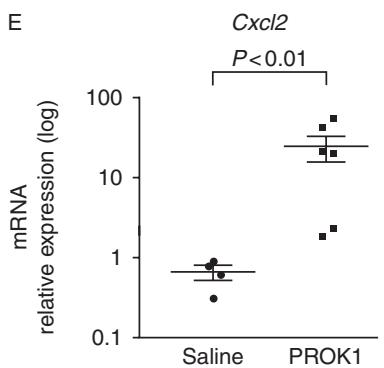

6

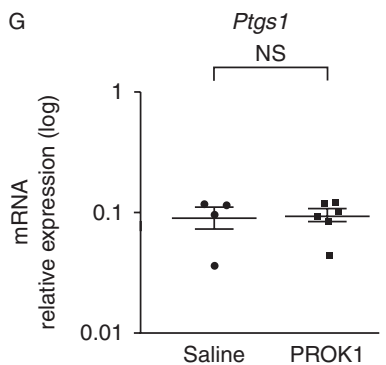

B

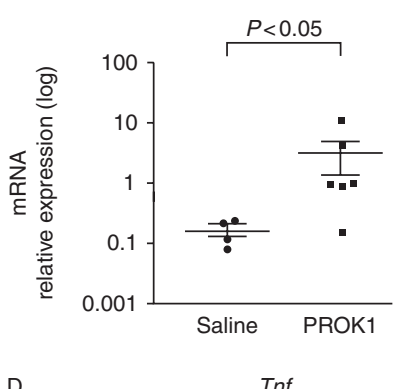

D

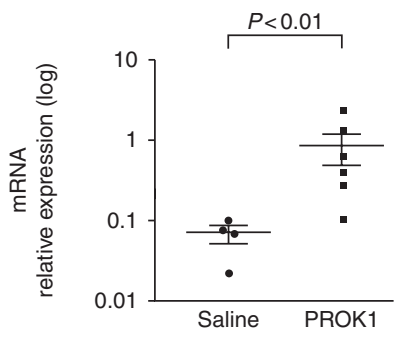

F

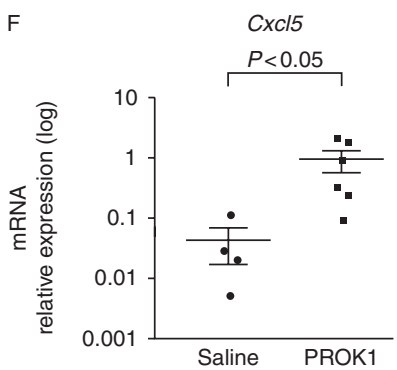

Figure 4 Intrauterine injection of PROK1 induces a pro-inflammatory response in murine fetal membranes. QPCR expression analysis of pro-inflammatory mediators (B) $1 / 6,(\mathrm{C}) \mathrm{I} 1 \mathrm{~b}$, (D) Tnf, (E) $\mathrm{CxCl} 2$ and (F) $\mathrm{CxCl} 5$ in murine membranes $6 \mathrm{~h}$ after intrauterine injection of PROK1 reveals their up-regulation but not of (A) Ptgs2 or (G) Ptgs1 (negative control). Each data point represents the mean response for each dam (three membranes per dam) and the graphs show the mean response per treatment group. Mean expression levels are in arbitrary units normalised to Actb mRNA, error bars represent \pm s.E.M. ( $t$-test). Saline ( $n=4$ dams) and PROK1 ( $n=6$ dams). NS, non-significant. Note: logarithmic scale.

a greater fold increase in expression of pro-inflammatory genes compared with PROK1 and those measured endogenously on D19 (apart from Cxc/5). Interestingly, it was the chemokines $\mathrm{CxCl} 2$ and $\mathrm{Cxc} / 5$ that showed the most striking differential expression in response to either term parturition or LPS treatment.

\section{Intrauterine injection of LPS but not PROK1 regulates production of pro-inflammatory mediators in amniotic fluid}

To compare the pro-inflammatory stimuli (LPS and PROK1), levels of secreted IL1B, TNF and CXCL2 were measured by ELISA in amniotic fluid collected $6 \mathrm{~h}$ after intrauterine injection (amniotic fluid was pooled from the amniotic sacs of four to six fetuses). Unexpectedly, a different pattern of results was obtained for each protein. IL1B was not regulated by either treatment, although PROK1 did demonstrate a trend for higher levels than LPS (saline, $46.60 \pm 7.72 \mathrm{pg} / \mathrm{ml}$; PROK1, 69.12 \pm $15.85 \mathrm{pg} / \mathrm{ml}$ and LPS, $41.03 \pm 9.96 \mathrm{pg} / \mathrm{ml}$; Fig. 5A). All samples from saline-treated animals contained undetectable levels of TNF, as did half of the PROK1-treated samples (saline, $0 \pm 0 \mathrm{pg} / \mathrm{ml}$ and PROK1, $1.30 \pm 0.60 \mathrm{pg} /$ $\mathrm{ml})$. By contrast, all LPS-treated samples contained detectable TNF $(47.95 \pm 18.67 \mathrm{pg} / \mathrm{ml})$ and the mean was significantly higher than the saline control $(P<0.05$; Fig. 5B). Measurement of CXCL2 revealed a similar pattern to TNF, with PROK1-treated samples demonstrating a trend for greater concentration than saline-treated samples (although not significant; saline, 50.57 \pm $7.60 \mathrm{pg} / \mathrm{ml}$ and PROK1, $101.00 \pm 21.33 \mathrm{pg} / \mathrm{ml}$ ) while the LPS-treated samples contained a significantly higher concentration $(1121.08 \pm 13.63 \mathrm{pg} / \mathrm{ml} ; P<0.01)$.

\section{Intrauterine injection of PROK1 does not induce PTD}

In order to investigate the effect of PROK1 on PTD, three groups of mice received intrauterine injection of saline, LPS or PROK1 on D17 of pregnancy (Fig. 6A). The time to delivery for mice treated with saline was $50.50 \pm$ $4.79 \mathrm{~h}(n=15)$. The time to delivery in dams treated with PROK1 (39.19 $\pm 4.87 \mathrm{~h} ; n=16)$ was not significantly different from the time to delivery in dams treated with saline. However, treatment with LPS significantly reduced the time to delivery $(17.90 \pm 2.65 \mathrm{~h} ; n=10)$ compared with treatment with saline $(P<0.001)$ or PROK1 $(P<0.05)$. To assess whether or not surgery itself affected time to delivery, the time taken for five dams to

Table 5 Fold changes in relative expression of pro-inflammatory mediators in mouse fetal membranes between D17 $(n=9)$ and D19 $(n=10)$ of pregnancy, between 6 -h saline $(n=4)$ and PROK1 $(n=6)$ intrauterine injection, and between 6-h saline and LPS $(n=4)$ intrauterine injection.

\begin{tabular}{lccc}
\hline Gene & $\begin{array}{c}\text { Endogenous } \\
\text { D17 vs 19 }\end{array}$ & $\begin{array}{c}\text { Saline vs } \\
\text { PROK1 }\end{array}$ & Saline vs LPS \\
\hline Ptgs2 & 1.73 & 2.61 & 13.74 \\
II6 & 12.04 & 18.68 & 62.80 \\
II1b & 11.08 & 17.74 & 81.43 \\
Tnf & 2.94 & 12.54 & 12.76 \\
Cxcl2 & 90.19 & 37.52 & 290.67 \\
CxCl5 & 440.16 & 22.45 & 62.26 \\
\hline
\end{tabular}


A

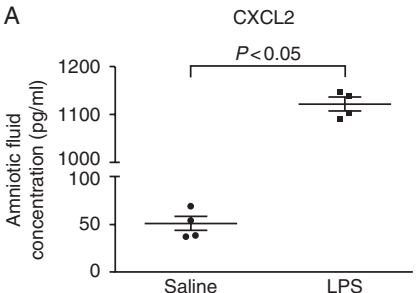

B

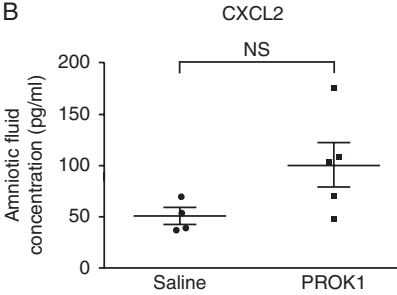

C

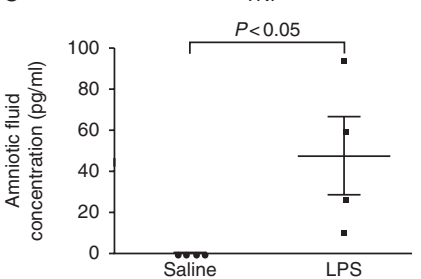

D

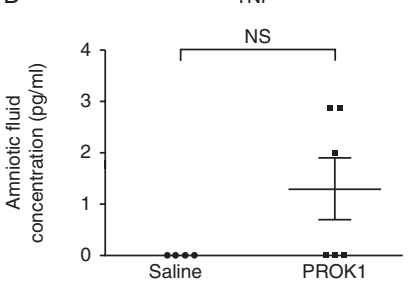

E
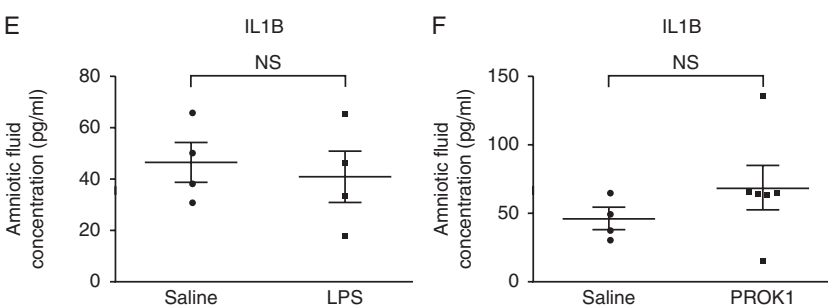

Figure 5 Intrauterine injection of LPS but not PROK1 increases the levels of secreted cytokines in murine amniotic fluid. Protein quantification of IL1B, TNF and CXCL2 by ELISA in amniotic fluid $6 \mathrm{~h}$ after intrauterine injection of LPS (A, C and E) or PROK1 (B, D and F) reveals significant up-regulation of TNF and CXCL2 in response to LPS but not PROK1 and no increase in IL1B to either treatment. Each data point represents the mean response for each dam (amniotic fluid from four to six sacs per dam) and the graphs show the mean response per treatment group. Mean expression levels $(\mathrm{pg} / \mathrm{ml})$, error bars represent \pm S.E.M. (t-test). NS, non-significant.

naturally deliver was recorded $(54.24 \pm 4.00 \mathrm{~h}$; not significantly different from the saline-treated group).

Another measure of the effect of infection-induced PTD is to record pup survival (Fig. 6B). The average percentage of pups surviving per dam (calculated from the number of live pups in the cage or in the dam at time of culling) was significantly reduced in mice treated with LPS $(15.33 \pm 6.08 \%)$ compared with treatment with saline or PROK1 $(88.57 \pm 3.22 \%$ and $82.87 \pm 4.46 \%$ respectively; $P<0.001)$.

\section{Discussion}

In humans, term parturition and PTD are considered proinflammatory events (Bowen et al. 2002, Challis et al. 2009, Catalano et al. 2010, Golightly et al. 2011). PROK1 mRNA expression is increased in human placenta and myometrium at term, and ex vivo treatment of these tissues with PROK1 induces a pro-inflammatory response (Denison et al. 2008, Gorowiec et al. 2011). Ex vivo treatment of term human myometrium with LPS up-regulates expression of PROK1 and PROKR1 (Gorowiec et al. 2011). In addition, PROK1 is a potent stimulator of smooth muscle contractions in the gut (Li et al. 2001, Wade et al. 2010). We hypothesised that PROK1 could be a potential mediator of proinflammatory pathways in human labour at term and may directly induce smooth muscle (myometrial) contractions. Thus, PROK1 induction may be part of the infection-induced pro-inflammatory response that contributes to PTD and antagonism of PROK1 could be a therapeutic target in the treatment of PTD.

We used the mouse as a model to investigate the role of prokineticins in parturition and PTD. Previously in the mouse, analysis of prokineticin expression in uteroplacental tissues has been restricted to the placenta (Hoffmann et al. 2007). Protein and mRNA expressions

A

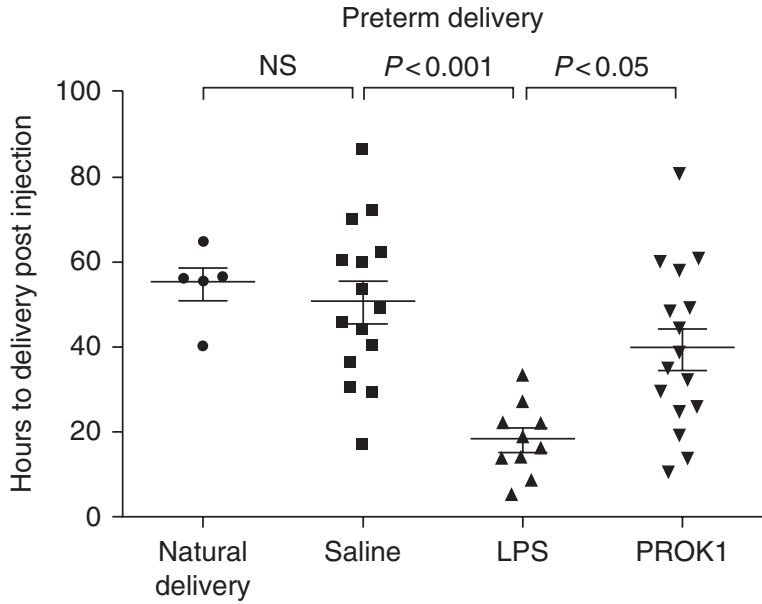

B

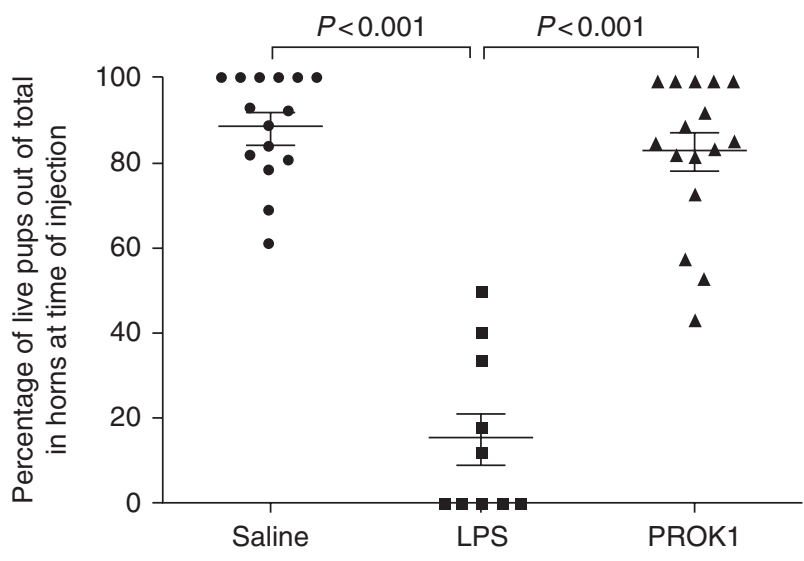

Figure 6 Intrauterine injection of PROK1 does not induce PTD. Time to delivery of first pup (A) and percentage pup survival per dam (B) following intrauterine injection of saline, LPS (20 $\mu \mathrm{g})$ or PROK1 (350 nM) were compared. The number of hours to natural delivery (nonsurgical) was not significantly different from saline-treated dams but LPS treatment significantly reduced the time to delivery. Error bars represent \pm S.E.M. (ANOVA). Natural delivery ( $n=5$ dams), saline ( $n=15$ dams), LPS ( $n=10$ dams) and PROK1 ( $n=16$ dams). NS, non-significant. 
of Prok1 and Prokr1 were examined on 9.5, 10.5, 14.5 and 17.5 days post-coitus (dpc) and expression of both was significantly down-regulated after $10.5 \mathrm{dpc}$, indicating a role in early placentation (Hoffmann et al. 2007). Therefore, we carried out the first daily examination of prokineticin expression in uteroplacental tissues preceding parturition in the mouse. Our data demonstrate that there is a dramatic up-regulation of Prok1 mRNA in fetal membranes on D18 of pregnancy, but unlike human tissue at term, there was no increase in uterine or placental Prok1. We confirmed localisation of the ligand PROK1 and the receptor PROKR1 in mouse fetal membranes by immunohistochemistry; thus, endogenous PROK1-PROKR1 signalling could occur in an autocrine and paracrine fashion. In addition, the stronger PROK1 stain observed on D19 indicates that the increase in Prok1 at the mRNA level is translated to increased protein expression. The up-regulation of Prok1 mRNA and protein suggests an early role for PROK1 signalling in mouse parturition.

Parturition can be prematurely induced in mice by intrauterine injection of a mimetic of infection such as LPS (Pirianov et al. 2009). Intrauterine injection mimics the major route of pathogen transmission in humans, ascending from the vagina and cervix to reach uteroplacental tissues where a local immune response is induced leading to immune cell recruitment, synthesis of prostaglandins, MMPs and ultimately PTD. Fetal membranes are an attractive uteroplacental tissue to target in the therapeutic treatment of PTD as infection or inflammation in fetal membranes will result in bi-directional release of pro-inflammatory mediators into the amniotic fluid (and fetus, potentially causing fetal inflammatory injury) or towards placenta and uterus contributing to the initiation of parturition (Myatt \& Sun 2010, Thiex et al. 2010).

In this study, we demonstrated that intrauterine treatment with PROK1 or LPS induces significant up-regulation of pro-inflammatory mediators in fetal membranes (I/6, I/1b, Tnf, Cxcl2 and Cxc/5). We also demonstrated that these pro-inflammatory genes are significantly up-regulated in fetal membranes on D19 of pregnancy (the day before parturition). Indeed, in vivo PROK1-mediated induction of Ptgs2, $/ 16$ and $/ 11 \mathrm{~b}$ cytokines by $6 \mathrm{~h}$ after treatment was comparable to that seen endogenously on D19 of pregnancy. These proinflammatory mediators are well documented to have important roles in term labour and PTD; for example, PTGS2 converts arachidonic acid into prostaglandins, which stimulate uterine smooth muscle contractions necessary for parturition (Challis et al. 1997), and inhibition of Ptgs2 significantly reduces LPS-induced PTD (Gross et al. 2000). Mice null for Il6 exhibit delayed labour and a reduced sensitivity to LPS-induced PTD (Robertson et al. 2010). I/1b mRNA levels increase in mouse uteroplacental tissues at term (Sato et al. 2001), and mice null for $1 / 1 b$ exhibit a reduced cytokine response to LPS (Reznikov et al. 1999). These data suggest that one possible role for endogenous PROK1 in fetal membranes could be to induce expression of other pro-inflammatory mediators leading to the induction of parturition at term. By contrast, our in vivo studies suggest that the up-regulation of pro-inflammatory mediators induced by exogenous PROK1 is insufficient to induce PTD. This may be because PTD requires greater production of pro-inflammatory mediators (for example at levels induced by LPS) in order to overcome any endogenous 'brake' on PTD.

This study identified that in response to LPS or PROK1 treatment, fetal membrane $\mathrm{CxCl} 2$ expression was more highly up-regulated than $\mathrm{CxCl5}$. Both are potent neutrophil CXC chemokines known to increase in response to LPS/infection in rodents and humans (Keelan et al. 2004, Harju et al. 2005). By contrast, at term parturition (D19 of pregnancy), the increase in $\mathrm{CxCl5}$ expression was greater than that in $\mathrm{CXCl2}$. CXCL5 is expressed by epithelium in response to IL1B and TNF in humans (Keelan et al. 2004). Therefore, the increase in murine $\mathrm{CxCl} 5$ in fetal membranes on D19 of pregnancy seems likely to reflect increased expression by fetal membrane epithelia; by contrast, $\mathrm{Cxcl} 2$ is produced by macrophages. Intriguingly, neutrophil depletion does not affect time to delivery (Timmons \& Mahendroo 2006) whereas macrophage depletion does prevent LPSinduced PTD (Gonzalez et al. 2011). Taken together, these data suggest that macrophage infiltration and elevated $\mathrm{Cx} / 2$ expression correlate with PTD, whereas elevated $\mathrm{CxCl} 5$ expression correlates with term parturition. Given that both CXCL2 and CXCL5 signal through the GPCR CXCR2, further research is warranted to investigate these chemokines as it may provide insight into the difference between the regulation of term parturition and PTD.

We also identified important differences between mouse and human prokineticin involvement in term labour and infection-induced PTD. Human myometrium and placenta (but not fetal membranes) exhibit a significant increase in PROK1 expression at labour (Gorowiec et al. 2011). In addition, LPS increases expression of PROK1 and PROKR1 in human uteroplacental tissues (Gorowiec et al. 2011). By contrast, here we found that only mouse fetal membranes showed a significant elevation of Prok1 preceding labour, and in vivo administration of LPS did not regulate murine expression of Prok1 or Prokr1 within $6 \mathrm{~h}$. These data suggest that PROK1 and PROKR1 in mouse fetal membranes are not among the early complement of LPS-induced cytokines. This finding corroborates with our result that although PROK1 itself is proinflammatory, intrauterine injection of PROK1 is not sufficient to induce PTL. This result may be due to the lack of significant up-regulation of the inflammatory markers at the protein level as demonstrated by ELISA for CXCL2, TNF and IL1B in amniotic fluid $6 \mathrm{~h}$ after 
treatment. It is possible that a later time point may have yielded a different result as there is a trend for increased protein expression in response to PROK1 and it was found that LPS did not significantly up-regulate IL1B in amniotic fluid by $6 \mathrm{~h}$.

Although the interval to birth was shorter after PROK1, this was not statistically significant. A post hoc power calculation shows that we would need 21 mice in each of the natural delivery groups and the PROK 1 group to have $90 \%$ power to show a difference (at the $5 \%$ significance level) in the interval to delivery in the two groups. This assumes equal numbers in each groups and that the mean and S.D. of the time to delivery remain the same in each group. Hence, our study is underpowered to determine whether the relatively subtle effect of PROK1 on shortening time to delivery by $28 \%$ is statistically significant. The effect of LPS was profound, shortening the interval to delivery by $74 \%$. Our study had $89 \%$ power to detect a shortening effect of PROK 1 of time to delivery by $37 \%$. We can be confident that any effect of PROK1 on inducing PTD (if it exists) is less than half as powerful as LPS in shortening the interval to delivery (in the doses given). In contrast to the possible type II error for a subtle effect of PROK1 on inducing PTD, there was no difference in pup survival between the PROK1 and the saline groups; thus, even if there is a modest effect of PROK1 on PTD, it does not compromise offspring survival.

At term, both humans and mice demonstrate elevated maternal inflammatory responsiveness while maintaining a relatively quiescent in utero environment (Orsi et al. 2007, Yuan et al. 2009). It has been hypothesised that this allows rapid induction of labour by priming the maternal inflammatory response to a trigger of parturition while protecting the fetus from fetal inflammatory injury that could be caused by premature exposure to inflammation. We have shown that classic markers of parturition increase significantly in fetal membranes on the day prior to labour (D19) while Prok1 increases on D18; therefore, the ability of PROK1 to induce expression of these pro-inflammatory markers suggests that the endogenous increase in Prok1 expression in fetal membranes on D18 may lead to induction of proinflammatory mediator expression and labour. Why we were unable to induce this with exogenous treatment on D17 remains unclear, although it is possible that a higher dose of PROK1 would have been more effective.

It has been demonstrated in fetal sheep lung that inflammation and immune cell recruitment in response to LPS treatment promotes lung maturation (Kallapur et al. 2005). This is an important factor in the survival and morbidity of the neonate (Jobe \& Ikegami 2001) and may even be a trigger for parturition produced by the fetus (Condon et al. 2004, Harju et al. 2005). Thus, the endogenous increase in Prok 1 and its relatively mild proinflammatory properties (compared with LPS) may promote fetal maturation and potentially the induction of term labour. This hypothesis is consistent with our finding that PROK1 treatment, although proinflammatory, did not reduce pup survival. We can also speculate that as time to delivery was unaffected in PROK1-treated dams, the endogenous pro-inflammatory role of PROK1 is not to induce parturition through induction of a strong inflammatory response but to promote fetal maturation. This hypothesis may be supported by our finding that Prok1 expression peaks on D18, and not on D19 like the other pro-inflammatory mediators analysed, suggesting that in the mouse, transient endogenous expression occurs rather than a prolonged amplification of pro-inflammatory mediator expression driven by PROK1 as hypothesised to occur in humans (Catalano et al. 2010, Gorowiec et al. 2011).

In conclusion, we have shown that PROK1 has a proinflammatory effect on fetal membranes but intrauterine injection is insufficient to induce PTD. However, we have shown that fetal membranes exhibit dynamic regulation of Prok1 prior to the up-regulation of other proinflammatory mediators before parturition. This suggests an alternate as yet unidentified role similar to that in fetal maturation processes in term parturition in the mouse. We have also demonstrated differences between human and mouse prokineticin expression and regulation in response to LPS in uteroplacental tissues, demonstrating that caution should be applied when using mouse models of PTD. Lastly, we have also contributed to the building body of evidence that PTD is not simply the premature induction of the same pro-inflammatory cascades seen at term by showing the difference in regulation of chemokines at term and in response to LPS, highlighting potentially new targets for the treatment of PTD.

\section{Supplementary data}

This is linked to the online version of the paper at http://dx.doi. org/10.1530/REP-13-0295.

\section{Declaration of interest}

Over the last 3 years (2010-2012), J E Norman has acted as a paid consultant to a small drug company (Preglem) with an interest in obstetric/gynaecological drugs and has acted as an unpaid consultant to Hologic (who manufacture fibronectin amongst others).

\section{Funding}

This work was supported by the MRC Development Gap Fund Grant A853/0105.

\section{Acknowledgements}

The authors would like to thank Phil Bennett and Bronwen Herbert at ICL for assistance with establishment of the mouse model of PTD and Lawrence Hutchinson for helpful comments on the manuscript. 


\section{References}

Akira S, Uematsu S \& Takeuchi O 2006 Pathogen recognition and innate immunity. Cell 124 783-801. (doi:10.1016/j.cell.2006.02.015)

Allport VC, Pieber D, Slater DM, Newton R, White JO \& Bennett PR 2001 Human labour is associated with nuclear factor- $\mathrm{\kappa} B$ activity which mediates cyclo-oxygenase-2 expression and is involved with the 'functional progesterone withdrawal'. Molecular Human Reproduction 7 581-586. (doi:10.1093/molehr/7.6.581)

Beck S, Wojdyla D, Say L, Betran AP, Merialdi M, Requejo JH, Rubens C, Menon R \& Van Look PF 2010 The worldwide incidence of preterm birth: a systematic review of maternal mortality and morbidity. Bulletin of the World Health Organization 88 31-38. (doi:10.2471/BLT.08.062554)

Bollapragada S, Youssef R, Jordan F, Greer I, Norman J \& Nelson S 2009 Term labor is associated with a core inflammatory response in human fetal membranes, myometrium, and cervix. American Journal of Obstetrics and Gynecology 104 e101-e111. (doi:10.1016/j.ajog.2008.08.032)

Bowen JM, Chamley L, Keelan JA \& Mitchell MD 2002 Cytokines of the placenta and extra-placental membranes: roles and regulation during human pregnancy and parturition. Placenta 23 257-273. (doi:10.1053/ plac.2001.0782)

Burd I, Bentz AI, Chai J, Gonzalez J, Monnerie H, Le Roux PD, Cohen AS, Yudkoff M \& Elovitz MA 2010 Inflammation-induced preterm birth alters neuronal morphology in the mouse fetal brain. Journal of Neuroscience Research 88 1872-1881. (doi:10.1002/jnr.22368)

Catalano RD, Lannagan TR, Gorowiec M, Denison FC, Norman JE \& Jabbour HN 2010 Prokineticins: novel mediators of inflammatory and contractile pathways at parturition? Molecular Human Reproduction 16 311-319. (doi:10.1093/molehr/gaq014)

Catalano RD, Wilson MR, Boddy SC \& Jabbour HN 2011 Comprehensive expression analysis of prostanoid enzymes and receptors in the human endometrium across the menstrual cycle. Molecular Human Reproduction 17 182-192. (doi:10.1093/molehr/gaq094)

Challis JR, Lye SJ \& Gibb W 1997 Prostaglandins and parturition. Annals of the New York Academy of Sciences 828 254-267. (doi:10.1111/j.17496632.1997.tb48546.x)

Challis JR, Lockwood CJ, Myatt L, Norman JE, Strauss JF III \& Petraglia F 2009 Inflammation and pregnancy. Reproductive Sciences 16 206-215. (doi:10.1177/1933719108329095)

Cheng MY, Bittman EL, Hattar S \& Zhou QY 2005 Regulation of prokineticin 2 expression by light and the circadian clock. BMC Neuroscience 6 17. (doi:10.1186/1471-2202-6-17)

Condon JC, Jeyasuria P, Faust JM \& Mendelson CR 2004 Surfactant protein secreted by the maturing mouse fetal lung acts as a hormone that signals the initiation of parturition. PNAS 101 4978-4983. (doi:10.1073/ pnas.0401124101)

Denison FC, Kelly RW, Calder AA \& Riley SC 1998 Cytokine secretion by human fetal membranes, decidua and placenta at term. Human Reproduction 13 3560-3565. (doi:10.1093/humrep/13.12.3560)

Denison FC, Battersby S, King AE, Szuber M \& Jabbour HN 2008 Prokineticin-1: a novel mediator of the inflammatory response in thirdtrimester human placenta. Endocrinology 149 3470-3477. (doi:10.1210/ en.2007-1695)

Dorsch M, Qiu Y, Soler D, Frank N, Duong T, Goodearl A, O'Neil S, Lora J \& Fraser CC 2005 PK1/EG-VEGF induces monocyte differentiation and activation. Journal of Leukocyte Biology 78 426-434. (doi:10.1189/ jlb.0205061)

Doyle SL \& O'Neill LA 2006 Toll-like receptors: from the discovery of NFKB to new insights into transcriptional regulations in innate immunity. Biochemical Pharmacology 72 1102-1113. (doi:10.1016/j.bcp.2006. 07.010)

Elovitz MA, Wang Z, Chien EK, Rychlik DF \& Phillippe M 2003 A new model for inflammation-induced preterm birth: the role of plateletactivating factor and toll-like receptor-4. American Journal of Pathology 163 2103-2111. (doi:10.1016/S0002-9440(10)63567-5)

Evans J, Catalano RD, Morgan K, Critchley HO, Millar RP \& Jabbour HN 2008 Prokineticin 1 signaling and gene regulation in early human pregnancy. Endocrinology 149 2877-2887. (doi:10.1210/en.2007-1633)

Evans J, Catalano RD, Brown P, Sherwin R, Critchley HO, Fazleabas AT \& Jabbour HN 2009 Prokineticin 1 mediates fetal-maternal dialogue regulating endometrial leukemia inhibitory factor. FASEB Journal 23 2165-2175. (doi:10.1096/fj.08-124495)
Fitzgibbon J, Morrison JJ, Smith TJ \& O'Brien M 2009 Modulation of human uterine smooth muscle cell collagen contractility by thrombin, $\mathrm{Y}-27632, \mathrm{TNF} \alpha$ and indomethacin. Reproductive Biology and Endocrinology 7 2. (doi:10.1186/1477-7827-7-2)

Friebe-Hoffmann U, Chiao JP \& Rauk PN 2001 Effect of IL-1 $\beta$ and IL-6 on oxytocin secretion in human uterine smooth muscle cells. American Journal of Reproductive Immunology 46 226-231. (doi:10.1034/ j.1600-0897.2001.d01-6.x)

Goepfert AR, Andrews WW, Carlo W, Ramsey PS, Cliver SP, Goldenberg RL \& Hauth JC 2004 Umbilical cord plasma interleukin-6 concentrations in preterm infants and risk of neonatal morbidity. American Journal of Obstetrics and Gynecology 191 1375-1381. (doi:10.1016/j.ajog.2004.06.086)

Goldenberg RL, Hauth JC \& Andrews WW 2000 Intrauterine infection and preterm delivery. New England Journal of Medicine 342 1500-1507. (doi:10.1056/NEJM200005183422007)

Goldenberg RL, Culhane JF, lams JD \& Romero R 2008 Epidemiology and causes of preterm birth. Lancet 371 75-84. (doi:10.1016/ S0140-6736(08)60074-4)

Golightly E, Jabbour HN \& Norman JE 2011 Endocrine immune interactions in human parturition. Molecular and Cellular Endocrinology 335 52-59. (doi:10.1016/j.mce.2010.08.005)

Gomez-Lopez N, Laresgoiti-Servitje E, Olson DM, Estrada-Gutierrez G \& Vadillo-Ortega F 2010 The role of chemokines in term and premature rupture of the fetal membranes: a review. Biology of Reproduction $\mathbf{8 2}$ 809-814. (doi:10.1095/biolreprod.109.080432)

Gonzalez JM, Franzke CW, Yang F, Romero R \& Girardi G 2011 Complement activation triggers metalloproteinases release inducing cervical remodeling and preterm birth in mice. American Journal of Pathology 179 838-849. (doi:10.1016/j.ajpath.2011.04.024)

Gorowiec MR, Catalano RD, Norman JE, Denison FC \& Jabbour HN 2011 Prokineticin 1 induces inflammatory response in human myometrium: a potential role in initiating term and preterm parturition. American Journal of Pathology 179 2709-2719. (doi:10.1016/j.ajpath.2011. 08.029)

Gross G, Imamura T, Vogt SK, Wozniak DF, Nelson DM, Sadovsky Y \& Muglia LJ 2000 Inhibition of cyclooxygenase-2 prevents inflammationmediated preterm labor in the mouse. American Journal of Physiology. Regulatory, Integrative and Comparative Physiology 278 R1415-R1423.

Haddad R, Tromp G, Kuivaniemi H, Chaiworapongsa T, Kim YM, Mazor M \& Romero R 2006 Human spontaneous labor without histologic chorioamnionitis is characterized by an acute inflammation gene expression signature. American Journal of Obstetrics and Gynecology 394 e391-e324. (doi:10.1016/j.ajog.2005.08.057)

Harju K, Ojaniemi M, Rounioja S, Glumoff V, Paananen R, Vuolteenaho R \& Hallman M 2005 Expression of toll-like receptor 4 and endotoxin responsiveness in mice during perinatal period. Pediatric Research $\mathbf{5 7}$ 644-648. (doi:10.1203/01.PDR.0000156212.03459.A9)

Hoffmann P, Feige JJ \& Alfaidy N 2006 Expression and oxygen regulation of endocrine gland-derived vascular endothelial growth factor/prokineticin-1 and its receptors in human placenta during early pregnancy. Endocrinology 147 1675-1684. (doi:10.1210/en.2005-0912)

Hoffmann P, Feige JJ \& Alfaidy N 2007 Placental expression of EG-VEGF and its receptors PKR1 (prokineticin receptor-1) and PKR2 throughout mouse gestation. Placenta 28 1049-1058. (doi:10.1016/j.placenta.2007. 03.008)

Hoffmann P, Saoudi Y, Benharouga M, Graham CH, Schaal JP, Mazouni C, Feige JJ \& Alfaidy N 2009 Role of EG-VEGF in human placentation: physiological and pathological implications. Journal of Cellular and Molecular Medicine 13 2224-2235. (doi:10.1111/j.1582-4934.2008. 00554.x)

Jobe AH \& Ikegami M 2001 Antenatal infection/inflammation and postnatal lung maturation and injury. Respiratory Research 2 27-32. (doi:10.1186/ rr35)

Kallapur SG, Moss TJ, Ikegami M, Jasman RL, Newnham JP \& Jobe AH 2005 Recruited inflammatory cells mediate endotoxin-induced lung maturation in preterm fetal lambs. American Journal of Respiratory and Critical Care Medicine 172 1315-1321. (doi:10.1164/rccm. 200506-1007OC)

Keelan JA, Yang J, Romero RJ, Chaiworapongsa T, Marvin KW, Sato TA \& Mitchell MD 2004 Epithelial cell-derived neutrophil-activating peptide-78 is present in fetal membranes and amniotic fluid at increased 
concentrations with intra-amniotic infection and preterm delivery. Biology of Reproduction 70 253-259. (doi:10.1095/biolreprod.103. 016204)

Kelly RW 2002 Inflammatory mediators and cervical ripening. Journal of Reproductive Immunology 57 217-224. (doi:10.1016/S0165-0378 (02)00007-4)

LeCouter J, Kowalski J, Foster J, Hass P, Zhang Z, Dillard-Telm L, Frantz G, Rangell L, DeGuzman L, Keller GA et al. 2001 Identification of an angiogenic mitogen selective for endocrine gland endothelium. Nature 412 877-884. (doi:10.1038/35091000)

Li M, Bullock CM, Knauer DJ, Ehlert FJ \& Zhou QY 2001 Identification of two prokineticin cDNAs: recombinant proteins potently contract gastrointestinal smooth muscle. Molecular Pharmacology 59 692-698. (doi:10.1124/mol.59.4.692)

Maldonado-Perez D, Evans J, Denison F, Millar RP \& Jabbour HN 2007 Potential roles of the prokineticins in reproduction. Trends in Endocrinology and Metabolism 18 66-72. (doi:10.1016/j.tem.2006. 12.002)

Maldonado-Perez D, Brown P, Morgan K, Millar RP, Thompson EA \& Jabbour HN 2009 Prokineticin 1 modulates IL-8 expression via the calcineurin/NFAT signaling pathway. Biochimica et Biophysica Acta 1793 1315-1324. (doi:10.1016/j.bbamcr.2009.03.008)

Menon R \& Fortunato SJ 2007 Infection and the role of inflammation in preterm premature rupture of the membranes. Best Practice \& Research. Clinical Obstetrics \& Gynaecology 21 467-478. (doi:10.1016/j. bpobgyn.2007.01.008)

Monnier J \& Samson M 2008 Cytokine properties of prokineticins. FEBS Journal 275 4014-4021. (doi:10.1111/j.1742-4658.2008.06559.x)

Myatt L \& Sun K 2010 Role of fetal membranes in signaling of fetal maturation and parturition. International Journal of Developmental Biology 54 545-553. (doi:10.1387/ijdb.082771lm)

Negri L, Lattanzi R, Giannini E, Metere A, Colucci M, Barra D, Kreil G \& Melchiorri P 2002 Nociceptive sensitization by the secretory protein Bv8. British Journal of Pharmacology 137 1147-1154. (doi:10.1038/sj. bjp.0704995)

Ngan ES \& Tam PK 2008 Prokineticin-signaling pathway. International Journal of Biochemistry \& Cell Biology 40 1679-1684. (doi:10.1016/j. biocel.2008.03.010)

Norman JE, Morris C \& Chalmers J 2009 The effect of changing patterns of obstetric care in Scotland (1980-2004) on rates of preterm birth and its neonatal consequences: perinatal database study. PLoS Medicine 6 e1000153. (doi:10.1371/journal.pmed.1000153)

Orsi NM, Gopichandran N, Bulsara H, Ekbote UV \& Walker JJ 2007 Regulation of maternal serum and amniotic fluid cytokine profiles in the mouse: possible roles in the onset of labour. Journal of Reproductive Immunology 75 97-105. (doi:10.1016/j.jri.2007.03.002)

Osman I, Young A, Ledingham MA, Thomson AJ, Jordan F, Greer IA \& Norman JE 2003 Leukocyte density and pro-inflammatory cytokine expression in human fetal membranes, decidua, cervix and myometrium before and during labour at term. Molecular Human Reproduction 9 41-45. (doi:10.1093/molehr/gag001)

Osman I, Young A, Jordan F, Greer IA \& Norman JE 2006 Leukocyte density and proinflammatory mediator expression in regional human fetal membranes and decidua before and during labor at term. Journal of the Society for Gynecologic Investigation 13 97-103. (doi:10.1016/ j.jsgi.2005.12.002)

Peltier MR 2003 Immunology of term and preterm labor. Reproductive Biology and Endocrinology 1 122. (doi:10.1186/1477-7827-1-122)

Pirianov G, Waddington SN, Lindstrom TM, Terzidou V, Mehmet H \& Bennett PR 2009 The cyclopentenone 15-deoxy-delta 12,14-prostaglandin J(2) delays lipopolysaccharide-induced preterm delivery and reduces mortality in the newborn mouse. Endocrinology 150 699-706. (doi:10. 1210/en.2008-1178)

Reznikov LL, Fantuzzi G, Selzman CH, Shames BD, Barton HA, Bell H, McGregor JA \& Dinarello CA 1999 Utilization of endoscopic inoculation in a mouse model of intrauterine infection-induced preterm birth: role of interleukin 1 $\beta$. Biology of Reproduction 60 1231-1238. (doi:10.1095/biolreprod60.5.1231)

Robertson SA, Christiaens I, Dorian CL, Zaragoza DB, Care AS, Banks AM \& Olson DM 2010 Interleukin-6 is an essential determinant of on-time parturition in the mouse. Endocrinology 151 3996-4006. (doi:10.1210/ en.2010-0063)
Romero R, Espinoza J, Goncalves LF, Kusanovic JP, Friel LA \& Nien JK 2006 Inflammation in preterm and term labour and delivery. Seminars in Fetal \& Neonatal Medicine 11 317-326. (doi:10.1016/j.siny.2006.05.001)

Sato TA, Gupta DK, Keelan JA, Marvin KW \& Mitchell MD 2001 Expression of interleukin-1 $\beta$ mRNA in murine uterine and gestational tissues: relationship with gestational age. American Journal of Reproductive Immunology 46 413-419. (doi:10.1034/j.1600-0897.2001.d01-33.x)

Shaw JL, Denison FC, Evans J, Durno K, Williams AR, Entrican G, Critchley HO, Jabbour HN \& Horne AW 2010 Evidence of prokineticin dysregulation in fallopian tube from women with ectopic pregnancy. Fertility and Sterility 94 1601-1608.e1. (doi:10.1016/j.fertnstert.2009.10.061)

Thiex NW, Chames MC \& Loch-Caruso RK 2010 Tissue-specific induction of COX-2 and prostaglandins in lipopolysaccharide-stimulated extraplacental human gestational membranes in a 2-chamber transwell culture system. Reproductive Sciences 17 1120-1129. (doi:10.1177/ 1933719110378344)

Thomson AJ, Telfer JF, Young A, Campbell S, Stewart CJ, Cameron IT, Greer IA \& Norman JE 1999 Leukocytes infiltrate the myometrium during human parturition: further evidence that labour is an inflammatory process. Human Reproduction 14 229-236. (doi:10.1093/ humrep/14.1.229)

Timmons BC \& Mahendroo MS 2006 Timing of neutrophil activation and expression of proinflammatory markers do not support a role for neutrophils in cervical ripening in the mouse. Biology of Reproduction 74 236-245. (doi:10.1095/biolreprod.105.044891)

Timmons B, Akins M \& Mahendroo M 2010 Cervical remodeling during pregnancy and parturition. Trends in Endocrinology and Metabolism 21 353-361. (doi:10.1016/j.tem.2010.01.011)

Tornblom SA, Klimaviciute A, Bystrom B, Chromek M, Brauner A \& EkmanOrdeberg G 2005 Non-infected preterm parturition is related to increased concentrations of IL-6, IL-8 and MCP-1 in human cervix. Reproductive Biology and Endocrinology 3 39. (doi:10.1186/1477-7827-3-39)

Tribe RM, Moriarty P, Dalrymple A, Hassoni AA \& Poston L 2003 Interleukin-1 $\beta$ induces calcium transients and enhances basal and store operated calcium entry in human myometrial smooth muscle. Biology of Reproduction 68 1842-1849. (doi:10.1095/biolreprod.102.011403)

Waddell JM, Evans J, Jabbour HN \& Denison FC 2011 CTGF expression is up-regulated by PROK1 in early pregnancy and influences HTR-8/Svneo cell adhesion and network formation. Human Reproduction 26 67-75. (doi:10.1093/humrep/deq294)

Wade PR, Palmer JM, Mabus J, Saunders PR, Prouty S, Chevalier K, Gareau MG, McKenney S \& Hornby PJ 2010 Prokineticin-1 evokes secretory and contractile activity in rat small intestine. Neurogastroenterology and Motility 22 e152-e161. (doi:10.1111/j.1365-2982.2009.01426.x)

Watari M, Watari H, DiSanto ME, Chacko S, Shi GP \& Strauss JF III 1999 Pro-inflammatory cytokines induce expression of matrix-metabolizing enzymes in human cervical smooth muscle cells. American Journal of Pathology 154 1755-1762. (doi:10.1016/S0002-9440(10)65431-4)

Xu P, Alfaidy N \& Challis JR 2002 Expression of matrix metalloproteinase (MMP)-2 and MMP-9 in human placenta and fetal membranes in relation to preterm and term labor. Journal of Clinical Endocrinology and Metabolism 87 1353-1361. (doi:10.1210/jc.87.3.1353)

Young A, Thomson AJ, Ledingham M, Jordan F, Greer IA \& Norman JE 2002 Immunolocalization of proinflammatory cytokines in myometrium, cervix, and fetal membranes during human parturition at term. Biology of Reproduction 66 445-449. (doi:10.1095/biolreprod66.2.445)

Yuan M, Jordan F, McInnes IB, Harnett MM \& Norman JE 2009 Leukocytes are primed in peripheral blood for activation during term and preterm labour. Molecular Human Reproduction 15 713-724. (doi:10.1093/ molehr/gap054)

Zaragoza DB, Wilson RR, Mitchell BF \& Olson DM 2006 The interleukin $1 \beta$-induced expression of human prostaglandin $\mathrm{F} 2 \alpha$ receptor messenger RNA in human myometrial-derived ULTR cells requires the transcription factor, NFкB. Biology of Reproduction 75 697-704. (doi:10.1095/ biolreprod.106.053439)

Received 9 July 2013

First decision 13 August 2013

Revised manuscript received 13 September 2013

Accepted 19 September 2013 